\title{
Increased $\beta$-catenin and c-myc expression predict aggressive growth of non-functioning pituitary adenomas: An assessment using a tissue microarray-based approach
}

\author{
CHUNHUI LIU ${ }^{1}$, YOUTU WU ${ }^{2}$, SHENGYUAN YU ${ }^{2}$, JIWEI BAI ${ }^{1}$, \\ CHUZHONG $\mathrm{LI}^{2}$, DAN WU ${ }^{3}$ and YAZHUO ZHANG ${ }^{1,2}$ \\ ${ }^{1}$ Neurosurgical Department, Beijing Tiantan Hospital; ${ }^{2}$ Beijing Neurosurgical Institute, Capital Medical University, \\ Beijing 100050; ${ }^{3}$ Neurological Department, Beijing Renhe Hospital, Beijing 102699, P.R. China
}

Received December 12, 2015; Accepted December 8, 2016

DOI: $10.3892 / \mathrm{mmr} .2017 .6169$

\begin{abstract}
Non-functional pituitary adenomas (NFPAs) account for $80 \%$ of pituitary adenomas with the majority of these exhibiting recurrences post-surgery. Overexpression of $\beta$-catenin and c-myc is common in numerous invasive tumors. The present study sought to investigate the correlation of $\beta$-catenin and c-myc expression levels with aggressive growth and recurrence of NFPAs, using immunohistochemical examination of tissue microarrays. Tissue microarrays comprised 212 NFPAs specimens and 10 healthy specimens as controls. NFPAs were categorized as non-aggressive or aggressive. Immunohistochemical examination was performed to determine the expression of $\beta$-catenin and c-myc. Correlation of the expression levels of $\beta$-catenin and c-myc with clinicopathological parameters, including aggressiveness and recurrence, were assessed by univariate, multivariate and logistic regression analysis. Increased expression of $\beta$-catenin and $c-m y c$ was detected in the majority of aggressive NFPAs specimens (71.1 and $88.7 \%$, respectively). There was a significant positive correlation between $\beta$-catenin and c-myc expression and aggressiveness $[\mathrm{P}=0.001$, Odds Ratio $(\mathrm{OR})=4.011 ; \mathrm{P}<0.001$, $\mathrm{OR}=30.833$ ]. Only $\beta$-catenin expression demonstrated a significant correlation with recurrence in NFPAs $(\mathrm{P}=0.021$, $\mathrm{OR}=2.571$ ). $\beta$-catenin and $\mathrm{c}$-myc were demonstrated to be potential biomarkers for aggressive NFPAs and in the future, $\beta$-catenin may serve as a marker for aggressive behavior and recurrence in NFPAs.
\end{abstract}

Correspondence to: Professor Yazhuo Zhang, Neurosurgical Department, Beijing Tiantan Hospital, Capital Medical University, 6 Tiantan Xili, Dongcheng, Beijing 100050, P.R. China

E-mail: zyz2004520@yeah.net

Abbreviations: NFPA, nonfunctioning pituitary adenoma; MRI, magnetic resonance imaging; TMA, tissue microarray; IHC, immunohistochemistry

Key words: $\beta$-catenin, c-myc, NFPAs, aggressive, recurrence

\section{Introduction}

Pituitary adenoma (PA), the third most frequently diagnosed intracranial tumor, accounts for $\sim 10-25 \%$ of all primary intracranial tumors (1). Although the majority of PAs are benign, several of them exhibit an aggressive behavior characterized by rapid cell growth and involvement of the contiguous structures. Based on the signs and symptoms secondary to the over-secretion of pituitary hormones by the tumor, PA is classified into two major groups; functional pituitary adenomas (FPAs) and non-FPAs (NFPAs). The latter accounts for $80 \%$ of pituitary macroadenomas (2). Although surgery is the primary option for treatment, NFPAs frequently have supraor parasellar extension, due to which total resection of tumor is often not possible. The residual tumor regrows in $12-58 \%$ of patients within a span of 5 years (3). The complex tumor pathology of NFPAs has served as a barrier to the development of effective therapeutic interventions. Identification of markers that can predict aggressive characteristics of NFPAs may aid in the treatment strategy and be of assistance in preventing recurrence.

Wnt signaling is known to regulate cell proliferation, polarity and cell death (4). Aberrant Wnt signal transduction pathway has been implicated in tumorigenesis and tissue invasion (5). Activation of the Wnt- $\beta$-catenin pathway results in the abnormal accumulation of free $\beta$-catenin in the nuclei of cancer cells. This in turn activates transcription factors such as T-cell factor, to induce the expression of target genes involved in cell proliferation, including c-myc (6). In addition to functioning as a transcriptional coactivator, $\beta$-catenin is known for its role as a cell adhesion protein (7). $\beta$-catenin links E-cadherin molecules to $\alpha$-catenin leading to strong cadherin-mediated cell adhesion (8). Aberrant expression of $\beta$-catenin has a role in cellular transformation, tissue invasion and metastasis (7).

c-myc is a potent oncogene that has been demonstrated to promote tumorigenesis in a wide range of tissues (9). Upregulated expression of c-myc in tumor cells occurs through several mechanisms, including gene amplification, chromosomal translocation, single nucleotide polymorphism in regulatory regions, mutation of upstream signal pathways and 
those that enhance the protein stability (10). This upregulation has a number of consequences in cancer cell biology (11).

Previous studies $(12,13)$ have demonstrated the over-activation of the Wnt-signal pathway in NFPAs. A previous study (14) using gene expression microarrays indicated that $\beta$-catenin and c-myc proteins were highly upregulated in NFPAs compared with normal pituitary tissues. In a subsequent study (12), reverse transcription-quantitative polymerase chain reaction (RT-qPCR) and western blot analysis were used to confirm the overexpression of the two proteins in aggressive NFPAs.

In the present study, the expression levels of $\beta$-catenin and c-myc proteins in NFPAs were investigated using immunohistochemical examination of tissue microarrays to assess their relevance as markers for predicting aggressiveness and recurrence of NFPAs.

\section{Materials and methods}

Subjects. A total of 212 NFPA specimens resected by trans-sphenoidal surgery from patients (age range, 24-75 years) between 2010 and 2012, were obtained from the Beijing Tiantan Hospital (Beijing, China). The specimens were classified into two groups; non-aggressive and aggressive. A total of 10 normal pituitary glands were obtained from a donation program and served as controls. The deceased donors comprised 6 males and 4 females, aged 21-45 years (mean, 35 years) and had succumbed to non-neurological diseases. NFPA and control samples were embedded in paraffin wax to make archival blocks to be used for tissue microarray (TMA). Prior to enrollment, written informed consent was obtained from all NFPA subjects. The study was approved by the Ethics Committee at Beijing Tiantan Hospital. All procedures performed in studies involving human participants were in accordance with the 1964 Helsinki declaration and its later amendments or comparable ethical standards.

All the cases met the following criteria: i) Each paraffin block contained a sufficiently sized specimen to enable the construction of TMAs; ii) no radiation therapy was administered prior to surgery; iii) clinical information, including endocrinological evaluation and imaging data, was available; and iv) complete follow-up data for a minimum of 3 years.

The biological behavior was assessed according to pre-operative magnetic resonance imaging (MRI)/computed tomography scanning. Aggressive adenomas were defined as fulfilling any of the following two conditions: i) Hardy classification grade III and IV (15); ii) Knosp classification grade III and IV (16).

Clinical and follow-up data. All patients were diagnosed based on pre-operative sella MRI and postoperative pathology. Postoperative sella MRI scans were performed within $72 \mathrm{~h}$ post-surgery to determine the remaining residual tumor. These were evaluated by two neuroradiologists and a neurosurgeon, all of whom were blinded to the patient characteristics. The follow-up data for each patient was obtained at 6-month intervals for the first 2 years. Tumor recurrence was investigated by serial sella MRI scans performed at one year following surgery, or in the event of recurrence of clinical symptoms, whichever was the earlier. Recurrence was defined as the presence of a new tumor in patients with total tumor resection, based on the first post-operative MRI scan, or evidence of new growth of an incompletely resected tumor on serial post-operative MRI scans compared with the immediate post-operative MRI scan. The follow-up data were collected for 3 years.

TMA construction. To check the quality of the tissues, 4- $\mu \mathrm{m}$ thick sections of paraffin-embedded tissue from the 212 NFPA specimens and the 10 control samples were stained with hematoxylin and eosin (H\&E). Three core biopsies of $2.0 \mathrm{~mm}$ diameter were selected from each sample and transferred to tissue microarrays using the Leica BOND-III fully automated arrayer (Leica Biosystems, Inc., Lincolnshire, IL, USA). The locations of the core samples were randomly ordered and blinded to the pathologist with regard to the identity on the TMA slides. In addition, 4- $\mu$ m thick sections of TMAs were obtained using a serial microtome and applied to positively-charged glass slides. The slides were heated in a water bath at $50^{\circ} \mathrm{C}$ and subsequently dewaxed and then rehydrated through graded alcohols. The slides were dried at room temperature for $24-48 \mathrm{~h}$ and stored at $-80^{\circ} \mathrm{C}$ for subsequent use. To minimize loss of antigenicity, TMA slides were processed within a week.

Immunohistochemistry (IHC). The tumor content and quality of all TMA slides were evaluated in advance with H\&E staining The TMAs were placed in the Leica BOND-III, which is a fully automated, random and continuous access slide-staining system that processes IHC tests simultaneously. Primary antibodies for $\beta$-catenin (1:100, cat. no. ab22656) and c-myc (1:100, cat. no. ab32072) (both from Abcam, Cambridge, UK) were used. The optimal titers of the primary antibodies for the remainder were determined on pre-experimental results. The slides were scanned into digital images using Aperio AT2 (Leica Biosystems, Inc.), then scored for staining positivity and intensity. A total of two neuropathologists, who were blinded to the clinical information of the patients, independently examined and scored each case. Differences in interpretation were resolved by a consensus.

Evaluation of immunohistochemical examination. The $\beta$-catenin staining was observed in the nucleus and c-myc staining in the cytoplasm and nucleus. The results were calculated using Aperio AT2 (v12.1.0.5029; Leica Biosystems, Inc.) with digital slide viewing software. The staining intensity for $\beta$-catenin and c-myc was scored as follows: 0, no; 1 , weak; 2 , moderate and 3 , high intensity. The distribution of positively stained cells was scored on a scale of $0-5$ with 0 for no staining; $1,<20 \% ; 2,20-40 \% ; 3,40-60 \%$; 4, 60-80\% and $5,80-100 \%$. The composite score was calculated as the staining intensity score $\mathrm{x}$ distribution score (score $\leq 6$, weak expression; $>6$, strong expression).

Statistical analysis. The chi-square test ( $\chi^{2} ;$ P-value) was used to determine the significance of the association between $\beta$-catenin expression, c-myc expression and clinical parameters that included aggressiveness and recurrence. Variables demonstrating a significant association with NFPA recurrence on univariate analysis were additionally subjected to multivariate analysis. Two-tailed $\mathrm{P}<0.05$ was considered to indicate a statistically significant difference. Survival rates 
were determined using logistic regression analysis. Analyses were performed using SPSS software, version 17.0 (SPSS, Inc., Chicago, IL, USA).

\section{Results}

Clinical and pathological features. All 212 NFPAs met the inclusion criteria. The details of their clinicopathological parameters are presented in Table I. At the time of the first surgical treatment, the age of the patients ranged between 24-75 years (mean, 50 years; median, 52 years). There were more male patients $(n=124,58.5 \%)$ compared with female patients $(n=88,41.5 \%)$. The aggressive group $(n=97)$ comprised $41(42.3 \%)$ females and $56(57.7 \%)$ males, while the non-aggressive group $(n=115)$ comprised 47 (40.9\%) females and $68(59.1 \%)$ males. Partial resection or minimum residual tumor was identified in $130(61.3 \%)$ of the total patients.

Tissue microarrays analysis; correlation of $\beta$-catenin and $c$-myc expression with aggressive behavior. TMA analysis to determine the correlation between $\beta$-catenin and c-myc expression in NFPA samples was determined by the immunohistochemical examination of TMA slides (Figs. 1 and 2). The score of $\beta$-catenin and c-myc staining in the normal pituitary tissues was significantly low compared with that in the non-aggressive $(1.6 \pm 0.27$ vs. 5.430.27; $\mathrm{P}=0.001)$ and aggressive tumors $(1.6 \pm 0.27$ vs. $9.18 \pm 0.41, \mathrm{P}<0.001)$. Similar results were observed with c-myc staining, where normal group demonstrated lower expression compared with the non-aggressive $(1.6 \pm 0.27$ vs. $5.57 \pm 0.29, \mathrm{P}=0.001)$ and aggressive tumors $(1.6 \pm 0.27$ vs. $9.8 \pm 0.43, \mathrm{P}<0.001)$, respectively. The association of protein expression with aggressive behavior was evaluated by the composite score of $\beta$-catenin and c-myc staining; $\sim 71.1 \%$ of aggressive NFPAs displayed strong $\beta$-catenin staining $(\mathrm{P}<0.01)$, and $28.7 \%$ c-myc overexpression $(\mathrm{P}<0.001$; Table II). However, of 115 non-aggressive NFPAs $69(60 \%)$ displayed weak $\beta$-catenin and 91 (70.1\%) weak c-myc staining.

Univariate analysis of the clinical characteristics indicated a significant correlation between $\beta$-catenin and c-myc expression and aggressive behavior $(\mathrm{P}<0.001$ and $\mathrm{P}<0.001$; Table II $)$. There was, in addition, a significant association between $\beta$-catenin and c-myc expression ( $\mathrm{P}=0.004$; Table II). However, the upregulation of the two proteins was not significantly associated with age, gender or tumor subtype (data not shown; Table II). Furthermore, multivariate analysis indicated a significant association between the overexpression of $\beta$-catenin alone with the aggressive behavior of tumors $(\mathrm{P}=0.001$; $\mathrm{OR}=4.011)$. There was no significant correlation between the expression of $\beta$-catenin with $\mathrm{c}$-myc $(\mathrm{P}<0.762 ; \mathrm{OR}=1.127)$.

Univariate analysis identified a significant association between the expression of $\beta$-catenin and c-myc and aggressive behavior $(\mathrm{P}<0.001$; Table II). No significant association with other clinicopathological parameters was observed (Table II). In the multivariate analysis, $c-m y c(P<0.001, O R=30.833)$ and $\beta$-catenin $(\mathrm{P}=0.001, \mathrm{OR}=4.011)$ were significantly associated with aggressive NFPAs (Table II).

Recurrence-free survival analysis. Follow-up data were available for all 212 patients. The patients were followed for 42 months. During follow-up, 41 (19.3\%) patients experienced
Table I. Clinical and pathological characteristics of study subjects.

\begin{tabular}{lrc}
\hline Characteristics & Patients (n=212) & Percentage \\
\hline Gender & & \\
Male & 124 & 58.5 \\
Female & 88 & 41.5 \\
Age (years) & & \\
Mean & 50 & \\
Median & 52 & \\
Aggressiveness & & \\
Aggressive & 97 & 45.8 \\
Non-aggressive & 115 & 54.2 \\
Subtype & & \\
Null cells & 148 & 69.8 \\
Gonadotrophs & 26 & 12.3 \\
Silent corticotrophs & 5 & 2.4 \\
Silent 3 & 33 & 15.5 \\
Surgical extent & & \\
Gross total resection & 82 & 38.7 \\
Residual & 130 & 61.3 \\
Recurrence (within 42 months) & & \\
Yes & 41 & 19.3 \\
No & 171 & \\
\hline
\end{tabular}

tumor recurrence (Table I). Univariate analysis indicated positive $\beta$-catenin staining $(\mathrm{P}=0.002)$ and tumor aggressiveness $(\mathrm{P}=0.004)$ to be significantly associated with recurrence, while other clinicopathological parameters and positive c-myc staining were not associated with NFPAs recurrence (Table III). Additional multivariate analysis identified a significant association between recurrence and $\beta$-catenin expression $(\mathrm{P}=0.021 ; \mathrm{OR}=2.571)$ and with tumor aggressiveness $(\mathrm{P}=0.043$; $\mathrm{OR}=2.158$; Table III).

\section{Discussion}

Aggressive behavior of tumors is the most important prognostic factor in patients with NFPAs. Complications of surgery, inability to achieve remission and inadequate therapy are problems associated with aggressiveness (17). There is no effective medical treatment for NFPAs, although post-operative radiotherapy is recommended for treatment of residual tumor and to prevent recurrence (18). Predicting the aggressive behavior of NFPAs may be a key contribution for therapeutic approaches and prognostic evaluation. In a previous study (12), the Wnt signaling pathway was demonstrated to be involved in tumorigenesis of aggressive NFPAs; RT-qPCR and western blotting analysis demonstrated overexpression of $\beta$-catenin and its downstream signal target c-myc in aggressive NFPAs. The proteins $\beta$-catenin and c-myc are considered to be useful markers of tumor progression in different types of solid tumors (19-23).

Until now, there has been no reported correlation of $\beta$-catenin and c-myc with different clinicopathological 
Table II. Univariate and multivariate analyses for clinical and pathologic variables related to aggressive non-functioning pituitary adenomas.

\begin{tabular}{|c|c|c|c|c|c|c|c|}
\hline \multirow[b]{2}{*}{ Characteristics } & \multicolumn{2}{|c|}{ Aggressiveness n (\%) } & \multicolumn{2}{|c|}{ Univariate analysis } & \multicolumn{3}{|c|}{ Multivariate analysis } \\
\hline & Yes $(n=97)$ & No $(n=115)$ & $\chi^{2}$ & P-value & Odds ratio & $95 \% \mathrm{CI}$ & P-value \\
\hline \multicolumn{8}{|l|}{ Gender } \\
\hline Male & $56(57.7 \%)$ & $68(59.1 \%)$ & 0.042 & 0.837 & & & \\
\hline Female & $41(42.3 \%)$ & $47(40.9 \%)$ & & & & & \\
\hline \multicolumn{8}{|l|}{ Age (years) } \\
\hline$<52$ & $51(52.6 \%)$ & $52(45.2 \%)$ & 1.141 & 0.285 & & & \\
\hline$\geq 52$ & $46(47.4 \%)$ & $63(54.8 \%)$ & & & & & \\
\hline \multicolumn{8}{|l|}{ Subtype } \\
\hline Null cell & $69(71.1 \%)$ & $79(68.7 \%)$ & 3.708 & 0.295 & & & \\
\hline Gonadotroph & $9(9.3 \%)$ & $17(14.8 \%)$ & & & & & \\
\hline Silent corticotroph & $4(4.1 \%)$ & $1(0.9 \%)$ & & & & & \\
\hline Silent 3 & $15(15.5 \%)$ & $18(15.6 \%)$ & & & & & \\
\hline \multicolumn{8}{|l|}{$\beta$-catenin } \\
\hline Weak & $28(28.9 \%)$ & $69(60 \%)$ & 20.55 & $<0.001$ & 4.011 & $1.830-8.788$ & 0.001 \\
\hline Strong & $69(71.1 \%)$ & $46(40 \%)$ & & & & & \\
\hline \multicolumn{8}{|l|}{ c-myc } \\
\hline Weak & $11(12.3 \%)$ & $91(70.1 \%)$ & 96.861 & $<0.001$ & 30.833 & $13.613-69.839$ & 0.001 \\
\hline Strong & $86(88.7 \%)$ & $24(20.9 \%)$ & & & & & \\
\hline
\end{tabular}

CI, confidence interval.

Aa

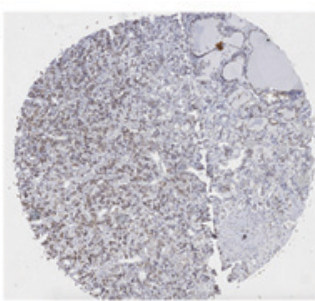

Ba

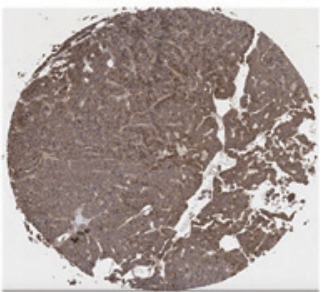

$\mathbf{C a}$

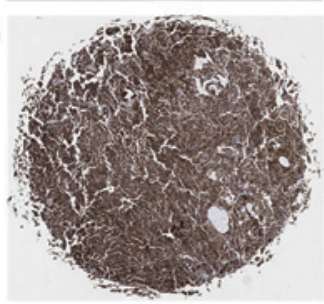

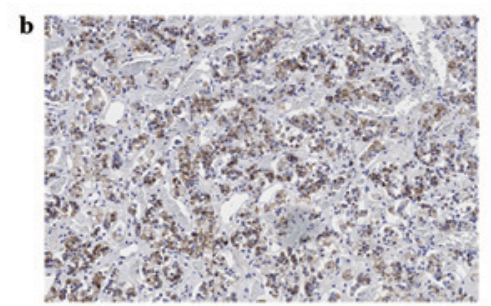

b
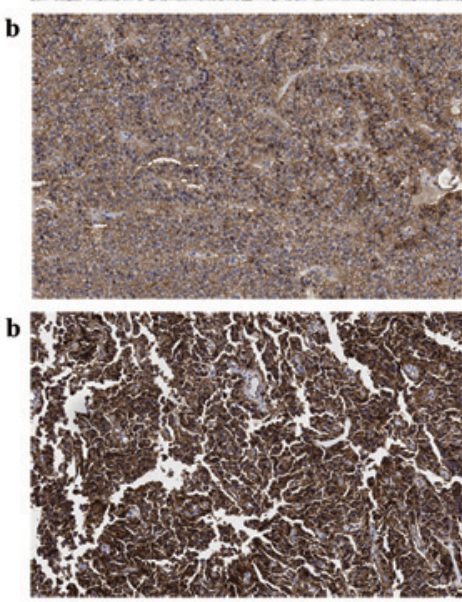

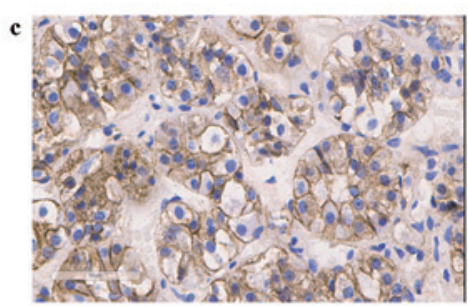

c
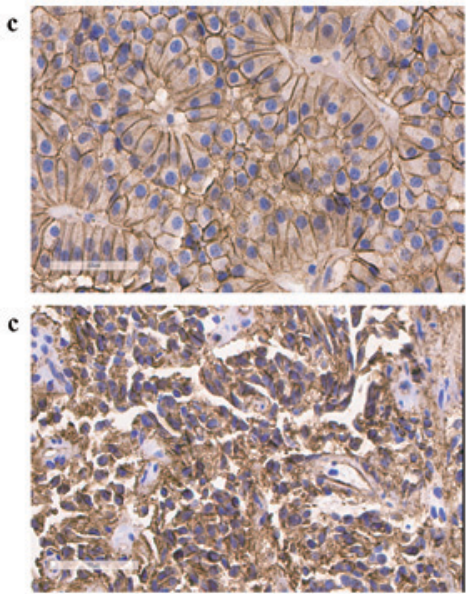

Figure 1. Immunohistochemical study showing expression of $\beta$-catenin tissue microarray. A-a (magnification, x1), A-b (magnification, x100), A-c (magnification, $\mathrm{x} 400$ ): Weak $\beta$-catenin-positive cells representative of normal pituitary tissues. B-a (magnification, x1), B-b (magnification, x100), B-c (magnification, $\mathrm{x} 400$ ): Weak $\beta$-catenin-positive cells representative of non-aggressive NFPAs. C-a (magnification, x1), C-b (magnification, x100), C-c (magnification, x400): Strong $\beta$-catenin-positive cells representative of aggressive NFPAs. NFPA, non-functioning pituitary adenoma.

parameters in NFPAs. The present study may be the first of its type to investigate this association; it studied the correlation of $\beta$-catenin and c-myc proteins with aggressiveness in NFPAs using IHC on tissue microarrays. The data demonstrated that 
Table III. Univariate and multivariate analyses for clinical and pathological variables associated with recurrence/progression-free survival.

\begin{tabular}{|c|c|c|c|c|c|c|c|}
\hline \multirow[b]{2}{*}{ Characteristics } & \multicolumn{2}{|c|}{$\begin{array}{c}\text { Recurrence } \\
\text { (within } 42 \text { months) }\end{array}$} & \multicolumn{2}{|c|}{ Univariate analysis } & \multicolumn{3}{|c|}{ Multivariate analysis } \\
\hline & Yes $(n=41)$ & No $(n=171)$ & $\chi^{2}$ & P-value & Odds ratio & $95 \% \mathrm{CI}$ & P-value \\
\hline \multicolumn{8}{|l|}{ Gender } \\
\hline Male & $23(56.1 \%)$ & $101(59.1 \%)$ & 0.77 & 0.781 & & & \\
\hline Female & $18(43.9 \%)$ & $70(40.9 \%)$ & & & & & \\
\hline \multicolumn{8}{|l|}{ Age } \\
\hline$<52$ & $23(56.1 \%)$ & $108(63.2 \%)$ & 3.124 & 0.077 & & & \\
\hline$\geq 52$ & $18(43.9 \%)$ & $63(36.8 \%)$ & & & & & \\
\hline \multicolumn{8}{|l|}{ Subtype } \\
\hline Null cell & $29(70.7 \%)$ & $119(69.6 \%)$ & 2.709 & 0.439 & & & \\
\hline Gonadotroph & $6(14.6 \%)$ & $20(11.7 \%)$ & & & & & \\
\hline Silent corticotroph & $2(4.9 \%)$ & $3(1.8 \%)$ & & & & & \\
\hline Silent 3 & $4(9.8 \%)$ & $29(16.9 \%)$ & & & & & \\
\hline \multicolumn{8}{|l|}{ Aggressiveness } \\
\hline Yes & 27 & 70 & 8.273 & 0.004 & 2.158 & $1.023-4.551$ & 0.043 \\
\hline No & 14 & 101 & & & & & \\
\hline \multicolumn{8}{|l|}{$\beta$-catenin } \\
\hline Weak & $10(24.4 \%)$ & $87(50.9 \%)$ & 9.348 & 0.002 & 2.571 & $1.150-5.747$ & 0.021 \\
\hline Strong & $31(75.6 \%)$ & $84(49.1 \%)$ & & & & & \\
\hline \multicolumn{8}{|l|}{ C-myc } \\
\hline Weak & $16(39.1 \%)$ & $85(49.7 \%)$ & 1.682 & 0.195 & & & \\
\hline Strong & $25(60.9 \%)$ & $86(50.3 \%)$ & & & & & \\
\hline \multicolumn{8}{|l|}{ Surgical extent } \\
\hline Gross total resection & $13(31.7 \%)$ & $69(40.4 \%)$ & 1.042 & 0.307 & & & \\
\hline Residual & $28(68.3 \%)$ & $102(59.6 \%)$ & & & & & \\
\hline
\end{tabular}

CI, confidence interval.

$\beta$-catenin and c-myc expression was increased in the aggressive NFPAs compared with the non-aggressive NFPAs and the normal pituitary tissues. On univariate analysis of $\beta$-catenin and c-myc expression, no statistical correlation was observed with respect to the clinicopathological parameters. However, they demonstrated a positive correlation with only aggressive behavior. Thus, $\beta$-catenin and c-myc can be used as biological markers for the detection of aggressive NFPAs. The results of the present study are consistent with those reported for other types of cancer. $\beta$-catenin and c-myc expression were upregulated in poor histological grade gastric cancers (24) and $\beta$-catenin expression was associated with higher grades in breast phyllodes tumors (25). The increased expression of c-myc was observed at a relatively late stage during progression in prostate cancer and it was demonstrated to correlate with tumor invasion and metastasis (26). Although a previous study reported the correlation of invasion with silent subtype 3 adenomas (26), no such clinicopathological association was identified by the present study.

The reported recurrent rates vary between different studies due to the difference in follow-up period and the number of patients enrolled $(27,28)$. In the present study, with a follow-up period of 42 months, the mean of recurrence was $19.3 \%$ (41/212) (Table I), which is marginally lower than previously reported (20-30\%). The follow-up period in these studies ranged between 2 months and 24 years $(27,29)$. This difference could be associated with the shorter follow-up in the present study and the variability in the definition of recurrence/progression.

To the best of our knowledge, the present study is the first investigation into the correlation of the expression levels of $\beta$-catenin and c-myc proteins with tumor recurrence in a large sample of NFPA specimens by using IHC on TMAs. The results are in agreement with another published report (30), which suggested that the aggressiveness of a tumor is an important pathological characteristic for assessing the risk of tumor recurrence. There is lack of data indicating association of $\beta$-catenin with recurrent NFPAs and the present study provided the first such evidence of a high $\beta$-catenin in immunohistochemical staining as being the most important pathological feature for assessing the risk of recurrence/progression of NFPAs.

The multivariate analysis demonstrated that an increased IHC positivity of $\beta$-catenin is a strong predictive factor of tumor recurrence. Although c-myc demonstrated a significant 
Aa

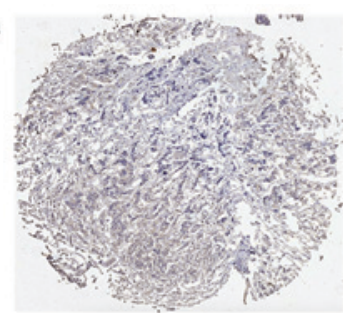

B a

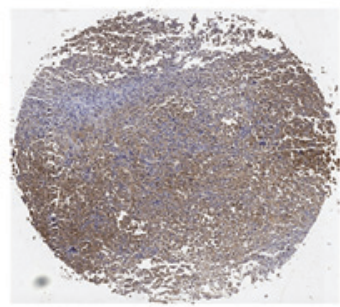

$\mathrm{C}_{\mathbf{a}}$

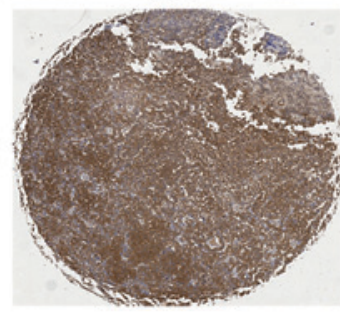

b

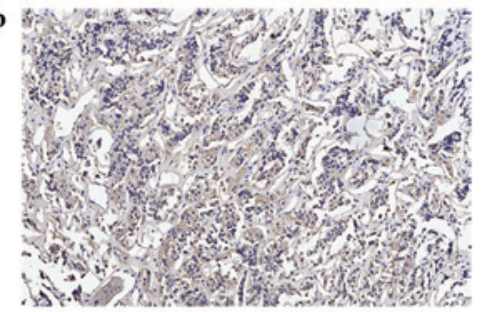

b

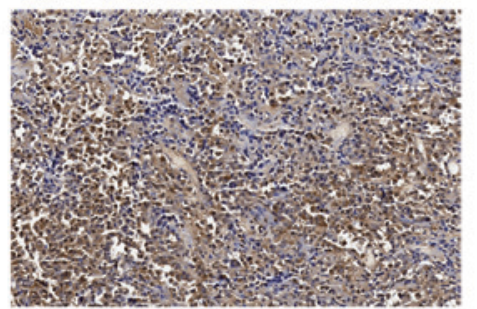

b

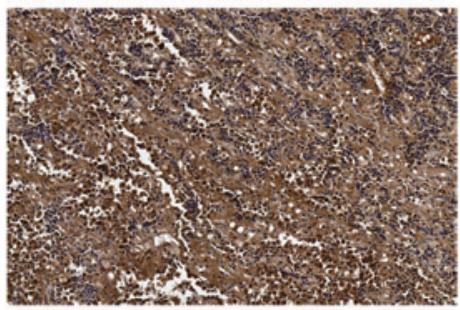

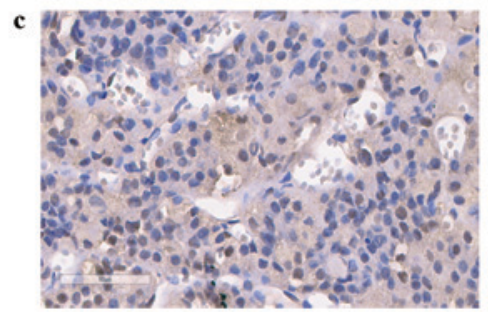

c
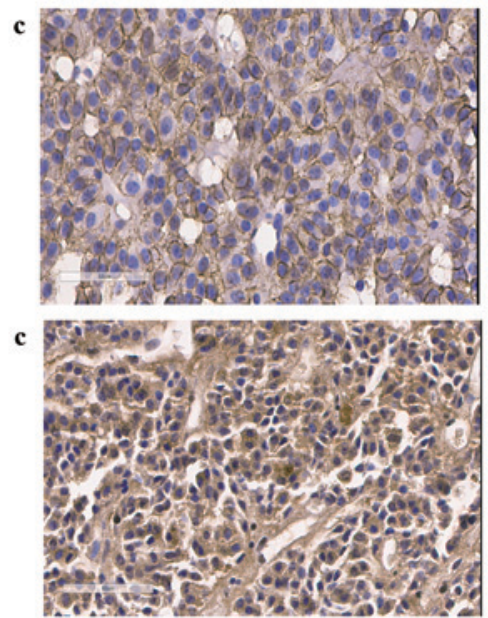

Figure 2. Expression of c-myc assessed by immunohistochemical examination on tissue microarray. A-a (magnification, x1), A-b (magnification, x100), A-c (magnification, x400): Weak c-myc -positive cells representative of normal pituitary tissues. B-a (magnification, x1), B-b (magnification, x100), B-c (magnification, x400): Weak c-myc-positive cells representative of non-aggressive NFPAs. C-a (magnification, x1), C-b (magnification, x100), C-c (magnification, x400): Strong c-myc-positive cells representative of aggressive pituitary adenomas. NFPA, non-functioning pituitary adenoma.

correlation with aggressive NFPAs, no other association of c-myc with recurrence was observed.

The observation that tumor resection is not associated with tumor recurrence is in agreement with the results reported by Brochier et al (3). They also reported that surgical extent is not an independent factor of recurrence in pituitary adenoma (31). This observation is in contrast to the results of previous studies $(30,31)$ that indicated tumor resection was a predictive factor for the recurrence of PA. The reason for this discrepancy in results can be attributed to combination of different types of PA, the difference in sample size and the length of follow-up duration in these studies, whereas the present study analyzed a homogenous group of NFPA samples. The follow-up data was analyzed using logistic regression analysis instead of the classical Kalpan Meier survival rate analysis. The survival time was not included to avoid discrepancy caused by the low recurrence rate. These may be two reasons for the inconsistency in results. Further studies are required to validate the results of the present study.

In conclusion, the present study suggested that $\beta$-catenin and c-myc can be a useful immunohistochemical marker for identifying aggressive NFPAs. Only after validation in a large number of samples can $\beta$-catenin be used for the prediction of recurrence of NFPAs following surgical resection.

\section{Acknowledgements}

The present study was supported by the National High-Tech Research and Development Program of China (grant no. 2014AA020610), the National Health and Family Planning Commission for Public Welfare Industry Research Project (grant no. 201402008), the National Natural Science Foundation of China (grant no. 3157060076) and the Natural Science Foundation of Beijing Municipality (grant no. 7144198).

\section{References}

1. Scheithauer BW, Gaffey TA, Lloyd RV, Sebo TJ, Kovacs KT, Horvath E, Yapicier O, Young WF Jr, Meyer FB, Kuroki T, et al: Pathobiology of pituitary adenomas and carcinomas. Neurosurgery 59: 341-353, 2006.

2. Saeger W, Lüdecke DK, Buchfelder M, Fahlbusch R, Quabbe HJ and Petersenn S: Pathohistological classification of pituitary tumors: 10 years of experience with the german pituitary tumor registry. Eur J Endocrinol 156: 203-216, 2007.

3. Brochier S, Galland F, Kujas M, Parker F, Gaillard S, Raftopoulos C, Young J, Alexopoulou O, Maiter D and Chanson P: Factors predicting relapse of nonfunctioning pituitary macroadenomas after neurosurgery: A study of 142 patients. Eur J Endocrinol 163: 193-200, 2010.

4. Clevers H and Nusse R: Wnt/beta-catenin signaling and disease. Cell 149: 1192-1205, 2012.

5. Herr P, Hausmann G and Basler K: WNT secretion and signalling in human disease. Trends Mol Med 18: 483-493, 2012.

6. Polakis P: The many ways of Wnt in cancer. Curr Opin Genet Dev 17: 45-51, 2007.

7. Jin T, George Fantus I and Sun J: Wnt and beyond Wnt: Multiple mechanisms control the transcriptional property of beta-catenin. Cell Signal 20: 1697-1704, 2008.

8. Michl P, Barth C, Buchholz M, Lerch MM, Rolke M, Holzmann KH, Menke A, Fensterer H, Giehl K, Löhr M, et al: Claudin-4 expression decreases invasiveness and metastatic potential of pancreatic cancer. Cancer Res 63: 6265-6271, 2003.

9. Sodir NM, Swigart LB, Karnezis AN, Hanahan D, Evan GI and Soucek L: Endogenous myc maintains the tumor microenvironment. Genes Dev 25: 907-916, 2011.

10. Wright JB, Brown SJ and Cole MD: Upregulation of c-MYC in cis through a large chromatin loop linked to a cancer risk-associated single-nucleotide polymorphism in colorectal cancer cells. Mol Cell Biol 30: 1411-1420, 2010. 
11. Lin CY, Lovén J, Rahl PB, Paranal RM, Burge CB, Bradner JE, Lee TI and Young RA: Transcriptional amplification in tumor cells with elevated c-myc. Cell 151: 56-67, 2012.

12. Wu Y, Bai J, Li Z, Wang F, Cao L, Liu C, Yu S, Yu G and Zhang Y: Low expression of secreted frizzled-related protein 4 in aggressive pituitary adenoma. Pituitary 18: 335-342, 2015.

13. Formosa R, Gruppetta M, Falzon S, Santillo G, DeGaetano J Xuereb-Anastasi A and Vassallo J: Expression and clinical significance of Wnt players and survivin in pituitary tumours. Endocr Pathol 23: 123-131, 2012.

14. Hong L, Wu Y, Feng J, Yu S, Li C, Wu Y, Li Z, Cao L, Wang F and Zhang Y: Overexpression of the cell adhesion molecule claudin-9 is associated with invasion in pituitary oncocytomas. Hum Pathol 45: 2423-2429, 2014.

15. Wilson CB: A decade of pituitary microsurgery. The Herbert Olivecrona lecture. J Neurosurg 61: 814-833, 1984

16. Knosp E, Steiner E, Kitz K and Matula C: Pituitary adenomas with invasion of the cavernous sinus space: A magnetic resonance imaging classification compared with surgical findings. Neurosurgery 33: 610-617, 1993.

17. Rosenquist M: 14-3-3 proteins in apoptosis. Braz J Med Biol Res 36: 403-408, 2003.

18. Kopp C, Theodorou M, Poullos N, Astner ST, Geinitz H, Stalla GK, Meyer B, Molls M, Nieder C and Grosu AL: Fractionated stereotactic radiotherapy in the treatment of pituitary adenomas. Strahlenther Onkol 189: 932-937, 2013.

19. Monga SP: $\beta$-Catenin signaling and roles in liver homeostasis, injury, and tumorigenesis. Gastroenterology 148: 1294-1310, 2015.

20. Cohen JB, Geyer SM, Lozanski G, Zhao W, Heerema NA, Hall NC, Nagar VA, Hemminger JA, Jones JA, Porcu P, et al: Complete response to induction therapy in patients with myc-positive and double-hit non-Hodgkin lymphoma is associated with prolonged progression-free survival. Cancer 120: 1677-1685, 2014.

21. Prensner JR, Chen W, Han S, Iyer MK, Cao Q, Kothari V, Evans JR, Knudsen KE, Paulsen MT, Ljungman M, et al: The long non-coding RNA PCAT-1 promotes prostate cancer cell proliferation through cMyc. Neoplasia 16: 900-908, 2014.
22. Lin YU, Wu T, Yao Q, Zi S, Cui L, Yang M and Li J: LGR5 promotes the proliferation of colorectal cancer cells via the Wnt/ $\beta$-catenin signaling pathway. Oncol Lett 9: 2859-2863, 2015.

23. Chiurillo MA: Role of the Wnt/ $\beta$-catenin pathway in gastric cancer: An in-depth literature review. World J Exp Med 5: 84-102, 2015.

24. Soutto M, Romero-Gallo J, Krishna U, Piazuelo MB, Washington MK, Belkhiri A, Peek RM Jr and El-Rifai W: Loss of TFF1 promotes Helicobacter pylori-induced $\beta$-catenin activation and gastric tumorigenesis. Oncotarget 6: 17911-17922, 2015.

25. Ho SK, Thike AA, Cheok PY, Tse GM and Tan PH: Phyllodes tumours of the breast: The role of CD34, vascular endothelial growth factor and $\beta$-catenin in histological grading and clinical outcome. Histopathology 63: 393-406, 2013.

26. Simpson DJ, Hibberts NA, McNicol AM, Clayton RN and Farrell WE: Loss of $\mathrm{pRb}$ expression in pituitary adenomas is associated with methylation of the RB1 CpG island. Cancer Res 60: 1211-1216, 2000.

27. Lee EH, Kim KH, Kwon JH, Kim HD and Kim YZ: Results of immunohistochemical staining of cell-cycle regulators: The prediction of recurrence of functioning pituitary adenoma. World Neurosurg 81: 563-575, 2014.

28. O'Sullivan EP, Woods C, Glynn N, Behan LA, Crowley R, O'Kelly P, Smith D, Thompson CJ and Agha A: The natural history of surgically treated but radiotherapy-naïve nonfunctioning pituitary adenomas. Clin Endocrinol (Oxf) 71: 709-714, 2009.

29. Wang EL, Qian ZR, Rahman MM, Yoshimoto K, Yamada S, Kudo E and Sano T: Increased expression of HMGA1 correlates with tumour invasiveness and proliferation in human pituitary adenomas. Histopathology 56: 501-509, 2010.

30. Dallapiazza RF, Grober Y, Starke RM, Laws ER Jr and Jane JA Jr: Long-term results of endonasal endoscopic transsphenoidal resection of nonfunctioning pituitary macroadenomas. Neurosurgery 76: 42-53, 2015.

31. Chang EF, Zada G, Kim S, Lamborn KR, Quinones-Hinojosa A, Tyrrell JB, Wilson CB and Kunwar S: Long-term recurrence and mortality after surgery and adjuvant radiotherapy for nonfunctional pituitary adenomas. J Neurosurg 108: 736-745, 2008. 